\title{
Urine Pregnancy Test before Rubella Vaccination among Reproductive Age Females: An Observation
}

\section{Teste de gravidez por urina antes de vacinação contra rubéola em mulheres com idade fértil: uma observação}

\author{
Won Sriwijitralai $^{1}$ Viroj Wiwanitkit ${ }^{2}$ \\ ${ }^{1}$ RV Medical Center, Bangkok, Thailand \\ ${ }^{2}$ Visiting professor, Hainan Medical University, Haikou, China
}

Rev Bras Ginecol Obstet 2016;38:160.

\section{Dear Editor}

Rubella is an important concern in obstetrics. It is a viral illness presenting with fever and skin rash. In a previous report on a seroprevalence study among pregnant women by Ferezin et $\mathrm{al}^{1}$, "no patient was positive for IgM, and IgG reactivity was $99.6 \%$." It should be noted that rubella is an extremely undesirable problem during pregnancy. Thus, the vaccine should be given prior to pregnancy. Nevertheless, an important concern is the contraindication of rubella vaccine for pregnant women. ${ }^{2}$ As a rule, there should be confirmation of no pregnancy before the physician can prescribe a rubella vaccine to a reproductive age female patient. Here, we share our experience from our perspective regarding the issue. The authors review results from urine pregnancy test screening before rubella vaccination among reproductive age females from 184 cases visiting our center seeking vaccination. All cases were healthy and mentioned no missed menstruation. Of the 184 cases, two (1.09\%) refused to undergo the urine pregnancy test and no further vaccination
Address for correspondence Won Sriwijitralai, RV Medical Center, Bangkok, Thailand (e-mail: wonsriwi@gmail.com).

was considered. Focusing on the remaining 182 cases, positive urine pregnancy was seen in two cases $(1.09 \%)$ and no further vaccination was considered. Of interest, there are some pregnancy cases detected by the screening confirming the need for urine pregnancy test screening. Although the patients give clear history of no symptoms of pregnancy, this can sometimes be bias or in disguise. In addition, some patients might reject screening and it is not possible to give vaccine in such cases.

\section{References}

1 Ferezin RI, Bertolini DA, Demarchi IG. [Prevalence of positive sorology for HIV, hepatitis B, toxoplasmosis and rubella in pregnant women from the northwestern region of the state of Paraná]. Rev Bras Ginecol Obstet 2013;35(2):66-70

2 Bhatt B, Jindal H, Malik JS, Choudhry S. Vaccination for pregnant women: need to address. Hum Vaccin Immunother 2014;10(12): 3627-3628 received

October 13, 2015

accepted

December 21, 2015

published online

February 2, 2016
DOI http://dx.doi.org/

10.1055/s-0036-1571473. ISSN 0100-7203.
Copyright $(2016$ by Thieme Publicações License terms Ltda, Rio de Janeiro, Brazil 